\title{
Infectious mononucleosis mimicking Epstein-Barr virus positive diffuse large B-cell lymphoma not otherwise specified
}

\author{
Tejaswi Kanderi*, 1(D) \& Maged S Khoory² \\ ${ }^{1}$ Department of Internal Medicine, UPMC Pinnacle Harrisburg Ringgold Standard Institution, 111 South Front Street, Harrisburg, \\ PA 17011, USA \\ ${ }^{2}$ Department of Hematology and Oncology, Carlisle Regional Cancer Center, Carlisle, PA 17015, USA \\ *Author for correspondence: tejaswi.kanderi@outlook.com
}

The Epstein-Barr virus (EBV) causes infectious mononucleosis (IM). In the case of atypical presentation, lymph node and tonsillar biopsies are required to rule out lymphoma. Here, we discuss an 83-year-old male who presented with findings suggestive of diffuse large B-cell lymphoma, which was later ruled out in favor of IM. The distinction between IM and lymphomas is quite challenging due to the extensive overlap between the two diseases. Various studies have demonstrated that EBV-positive diffuse large B-cell lymphoma mimics IM due to large B-cell proliferation in acute EBV infection. We suggest testing for acute EBV infection in addition to utilizing advanced testing to confirm IM in patients with atypical infection, to avoid misdiagnosis leading to inappropriate treatment.

First draft submitted: 15 January 2020; Accepted for publication: 4 June 2020; Published online: 17 July 2020

Keywords: diffuse large B cell lymphoma • Epstein Barr virus • immunohistochemistry • infectious mononucleosis - monospot test

Epstein-Barr virus (EBV) is a human herpesvirus 4, which causes infectious mononucleosis (IM) and is also noted to cause tumors [1]. The diagnosis of IM is through clinical features and laboratory analysis [2]. Acute EBV infection is characterized by fever, fatigue, pharyngitis/tonsillitis, cervical lymphadenopathy and splenomegaly. Laboratory manifestations include lymphocytosis, peripheral smear with $>10 \%$ atypical lymphocytes, positive monospot test, EBV antibodies in the serum and at times elevated liver enzymes and hyperbilirubinemia. Atypical presentation of IM is encountered often in the extremes of a population due to an immunocompromised state. In the case of atypical presentation, lymph node and tonsillar biopsies are required to rule out lymphoma [3,4]. However, biopsies can lead to misdiagnosis, as acute EBV in lymphoid tissue can mimic both Hodgkin's and non-Hodgkin's lymphoma (NHL) resulting in inappropriate diagnosis and treatment $[2,5]$.

EBV causes tumor formation by modifying B-cell growth transcription factors [6,7]. The spectrum of B-cell neoplasms associated with EBV infection has increased exponentially, with research demonstrating that EBVpositive diffuse large B-cell lymphoma (DLBCL) mimics IM due to large B-cell proliferation in acute EBV infection.

Here, we discuss an 83-year-old male who presented with findings suggestive of DLBCL, the most common form of NHL, which was later ruled out in favor of a diagnosis of IM.

\section{Patient}

An 83-year-old male with a medical history of hypertension, hyperlipidemia, coronary artery disease after requiring a drug-eluting stent and osteoarthritis, presents to the emergency department complaining of generalized abdominal pain and back pain. Initial examination of the patient's vitals demonstrated a temperature of $97.2^{\circ} \mathrm{F}\left(32.2^{\circ} \mathrm{C}\right)$, pulse rate of $70 / \mathrm{min}$, blood pressure of $135 / 68 \mathrm{~mm} \mathrm{Hg}$ and respiratory rate of $20 / \mathrm{min}$, saturating well on room air. The physical exam was significant for jaundice and bilateral lower extremity pitting edema. 


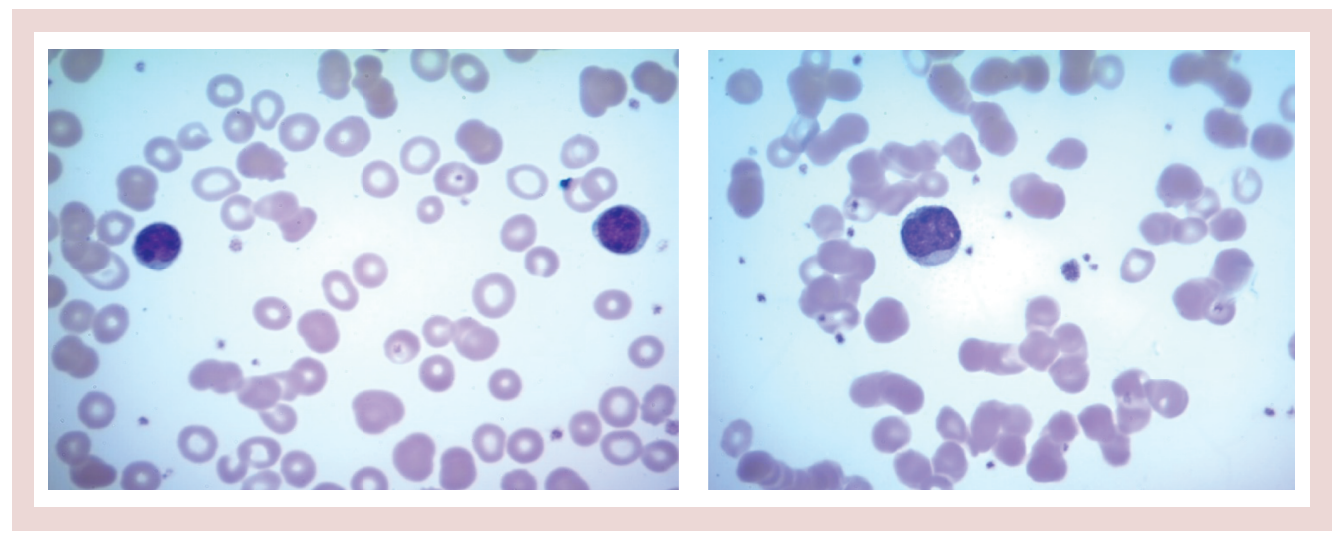

Figure 1. Peripheral smear showing characteristic atypical lymphocytes.

Complete blood count identified a white count of 11.7 (reference 4-9) and platelets of 116 (reference 150-350). Differential complete blood count revealed 51\% lymphocytosis (reference 15-40\%) and 38\% neutrophils (reference $50-75 \%$ ). Significant labs included elevated total bilirubin of $6.7 \mathrm{mg} / \mathrm{dl}$ (reference $<1$ ), aspartate transaminase of $325 \mathrm{U} / 1$ (reference <40), alanine transaminase of $340 \mathrm{U} / 1$ (reference $<60$ ), alkaline phosphatase of $702 \mathrm{U} / 1$ (reference $<100$ ), creatinine $1.43 \mathrm{mg} / \mathrm{dl}$ (baseline 0.8 ), lactate dehydrogenase $>500 \mathrm{U} / \mathrm{l}$ (reference $<200$ ), ferritin $>8000 \mathrm{ng} / \mathrm{ml}$ (reference <320). A computed tomography scan of the abdomen and pelvis with contrast revealed splenomegaly, mediastinal, retroperitoneal, intraabdominal (in porta hepatis and pancreatic head), pelvic and right inguinal lymphadenopathy.

Monospot test is positive. A peripheral smear revealed atypical lymphocytes $2+$, few target cells, smudge cells $2+$ and giant platelets (Figure 1).

Immunoglobulin assay revealed elevated serum IgG and circulating IgA with normal IgM levels. IgM and IgG antibodies against EBV viral capsid antigen (VCA) and $\operatorname{IgG}$ antibody against EBV nuclear antigen were positive, suggesting a recent $\mathrm{EBV}$ infection.

The values of the antibody panel were as follows:

- EBV Nuclear Ag IgG: 38.20 U/ml (normal <18 U/ml) EBV VCA Ab IgM: 136 U/ml (normal <36 U/ml) EBV VCA Ab IgG: $32.50 \mathrm{U} / \mathrm{ml}$ (normal $<18 \mathrm{U} / \mathrm{ml}$ ).

With an extremely high suspicion for malignancy, an inguinal lymph node biopsy was recommended and the patient was referred to Hematology-Oncology. Preliminary biopsy results demonstrated diffuse proliferation of abnormal large lymphoid cells suspicious for lymphoma (Figure 2).

Final biopsy results revealed EBV-positive DLBCL not otherwise specified (EBV+ DLBCL, not otherwise specified [NOS]), with a diffuse proliferation of large neoplastic lymphocytes, extensive necrosis, brisk mitotic activity, nuclei and nucleoli of varying morphology and size, with some cells reaching immunoblastic morphology (Figure 3).

Immunohistochemistry determined B-cells positive for CD20, CD79a and PAX5, but negative for ALK1, BCL2, BCL6 and CD10. Immunohistochemistry also revealed the overexpression of C-myc (images unavailable). Fluorescence in situ hybridization (FISH) was positive for EBER (EBV-encoded small RNAs) with lambda light chain restriction. Ki-67 showed high proliferation with $80-90 \%$ nuclear labeling in tumor cells. Flow cytometry determined abnormal large B-cell populations lacking light chains. Differential flow cytometry revealed $86.8 \%$ of lymphocytes with $78 \%$ of B cells and $22 \%$ of $\mathrm{T}$ cells with an inverted CD4/CD8 ratio of 0.8 .

FISH also indicated the absence of gene rearrangements in BCL2, BCL6 and MYC revealing conflicting results between flow cytometry and FISH. The patient was followed closely for hepatic enzymopathy and development of any new symptoms as the clinical picture was leaning toward IM and drifting away from lymphoma, given positive monospot test and serology and a negative BCL2. He was started on dexamethasone tapper for 4 days, with an idea to subside inflammation as the bilirubin level continue to rise. Bilirubin and liver enzymes trended up and normalized over the next 4-8 weeks. Figures 4-7 highlight the specific trends of bilirubin, aspartate aminotransferase, alanine aminotransferase and alkaline phosphatase. 


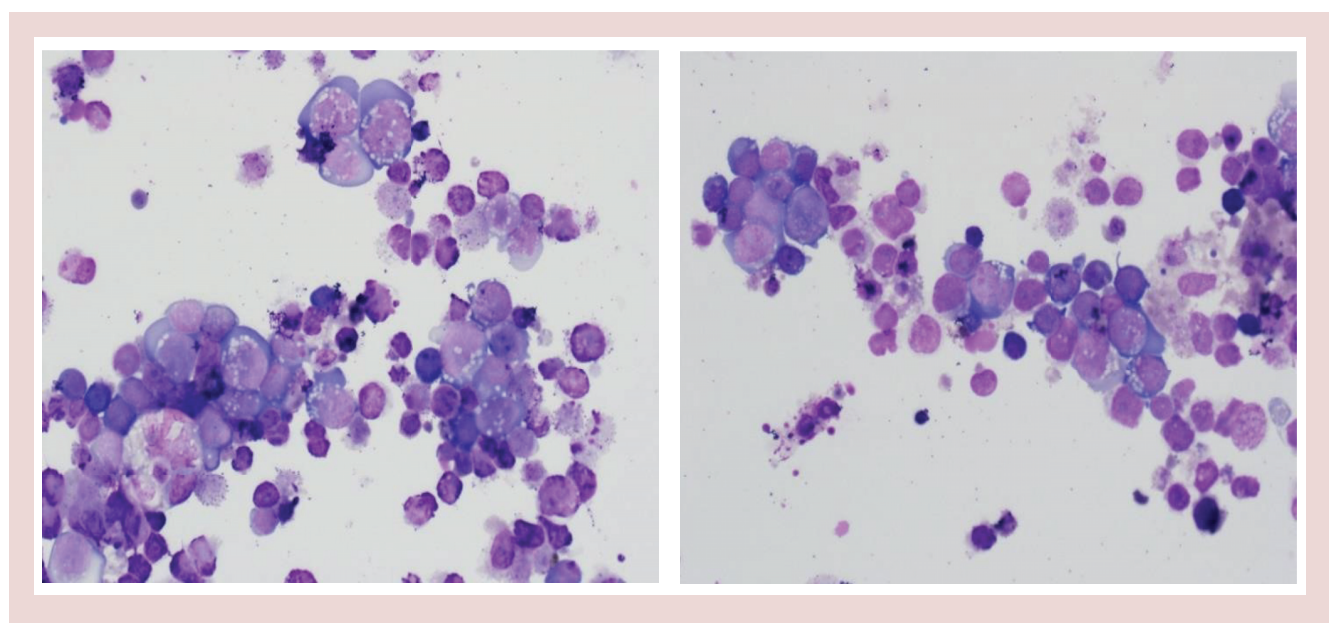

Figure 2. An imprint of lymph node biopsy: variably enlarged atypical lymphoid cells with basophilic, vacuolated cytoplasm. Atypical lymphoid cells appear more polymorphous in Epstein-Barr virus infection than diffuse large B-cell lymphoma.

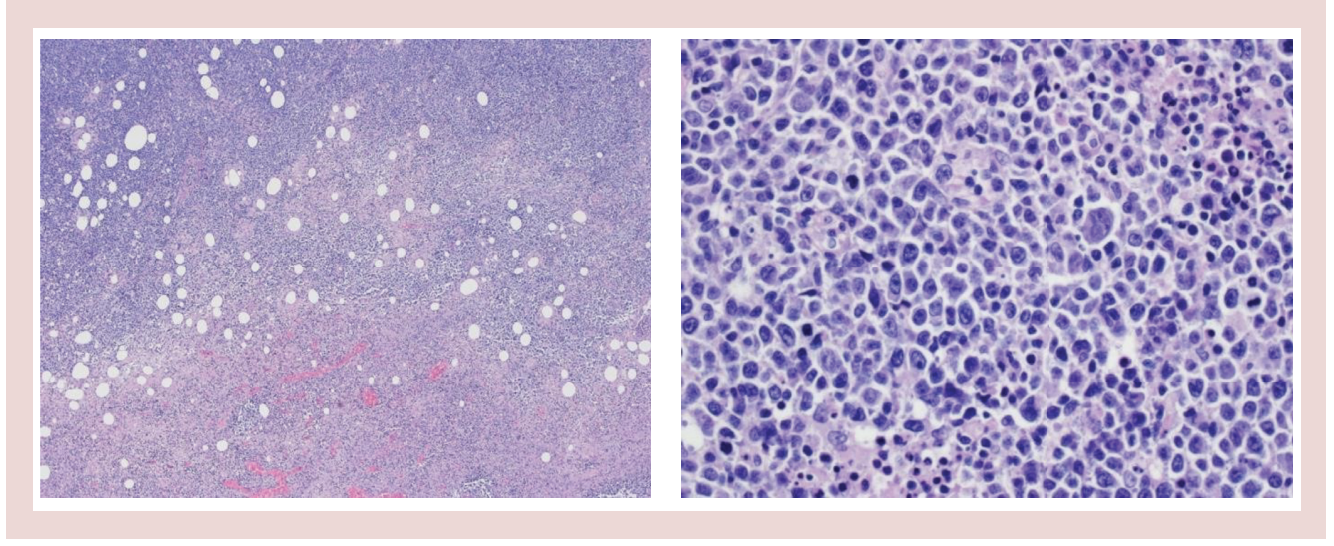

Figure 3. Histology: effaced architecture with areas of necrosis.

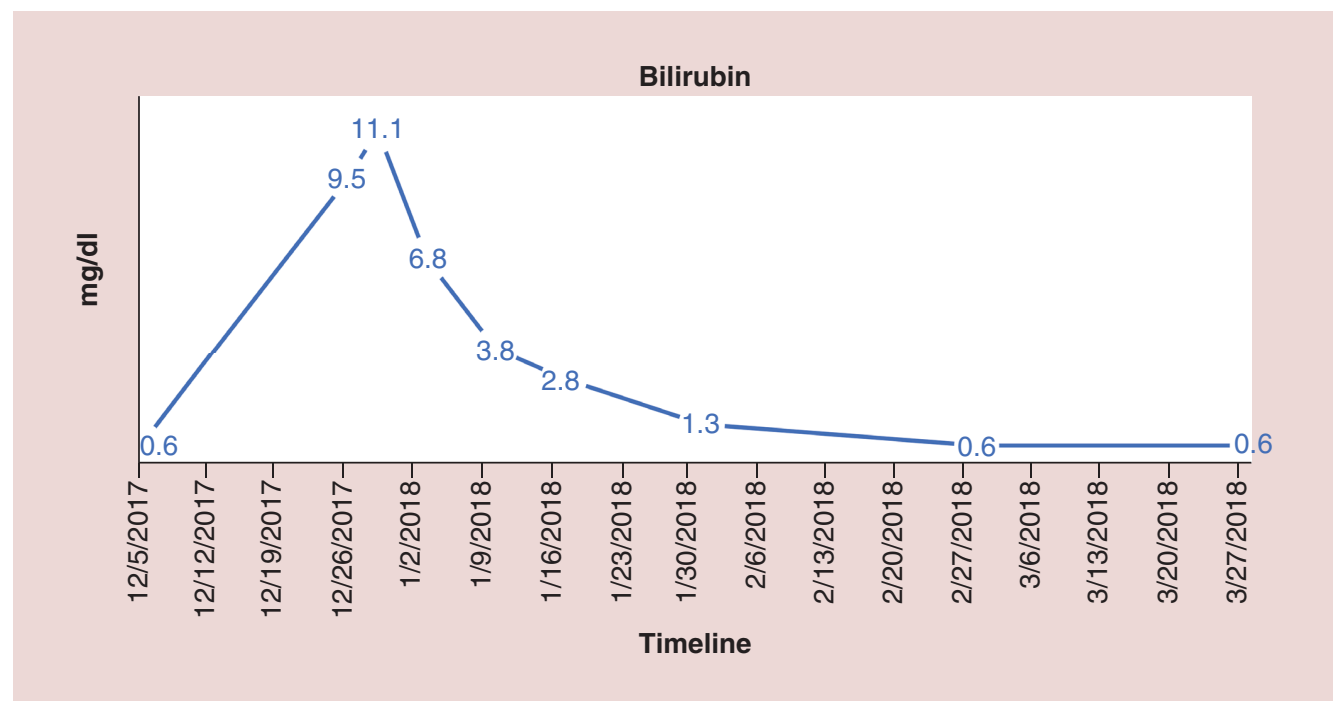

Figure 4. Trend of bilirubin levels. 


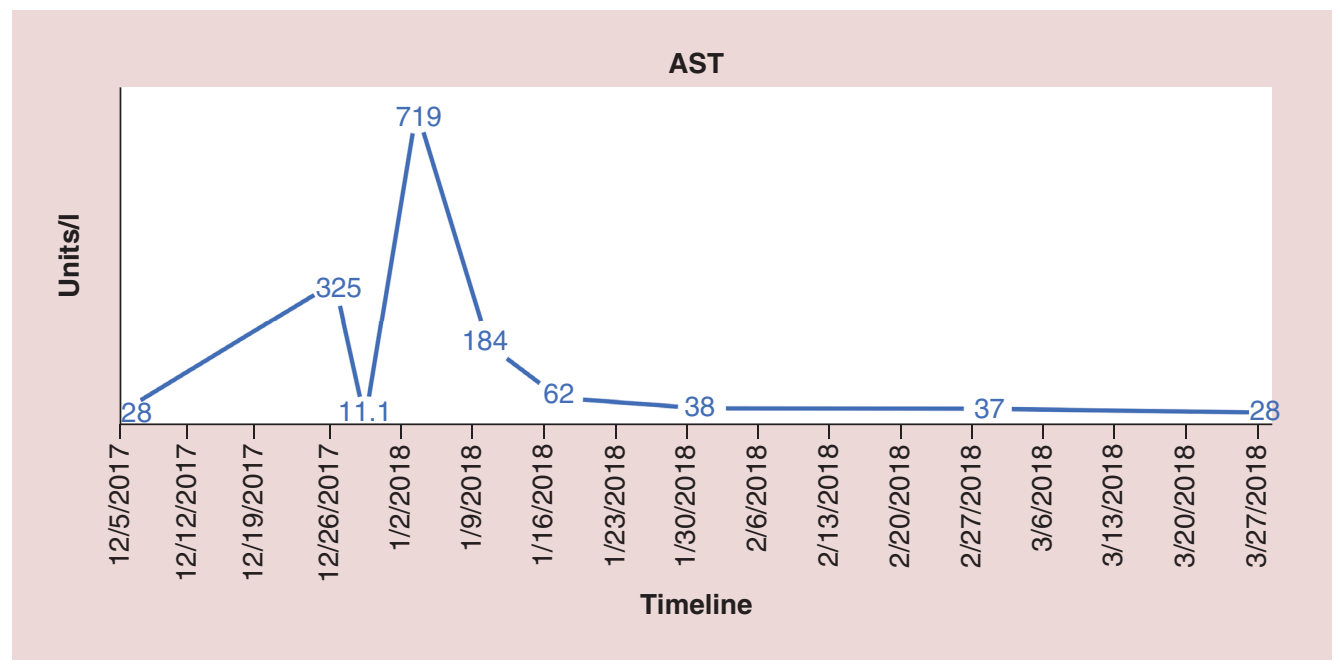

Figure 5. Trend of aspartate aminotransferase levels. AST: Aspartate aminotransferase.

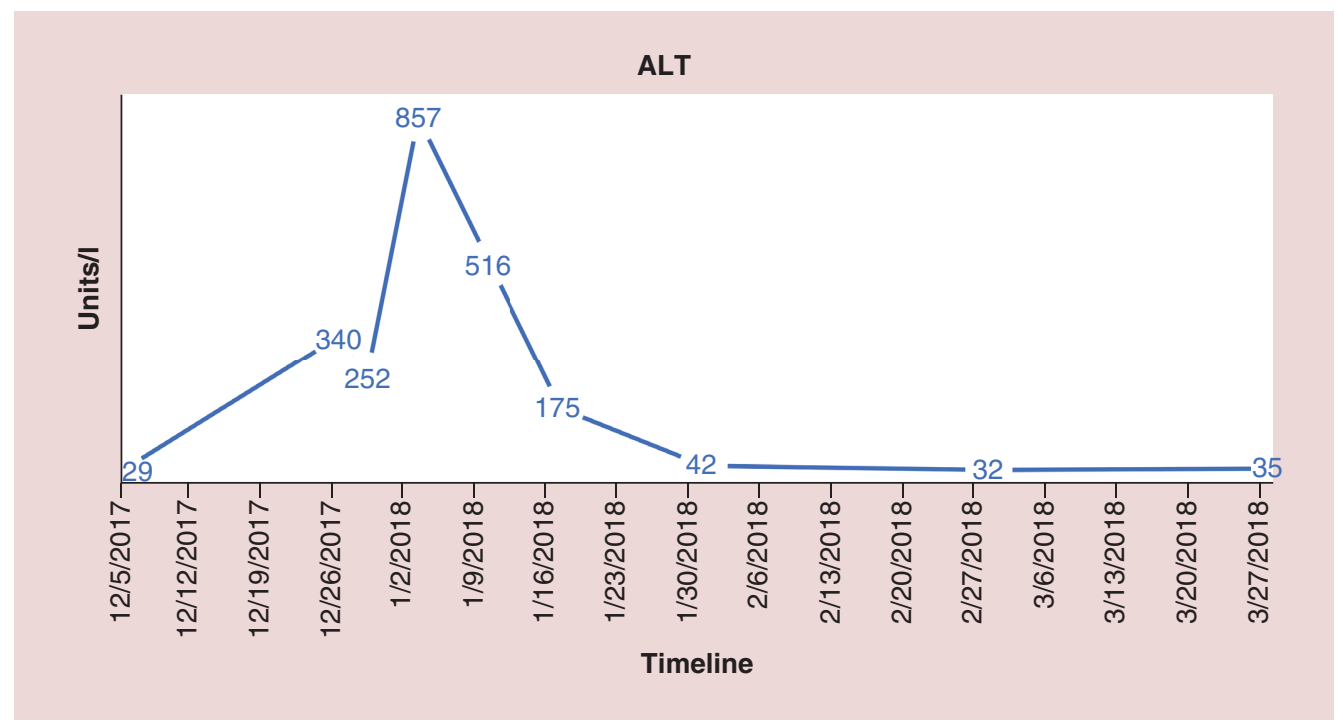

Figure 6. Trend of alanine aminotransferase levels. ALT: Alanine aminotransferase.

Interestingly, follow-up positron emission tomography/computerized tomography, performed 4 months after the initial imaging demonstrated normalization of all previously documented extensive lymphadenopathy and splenomegaly, which further strengthened the diagnosis of IM.

\section{Discussion}

EBV is the most potent human virus that transforms in vivo. It can persist for life in greater than $90 \%$ of humans without causing disease. EBV spreads through saliva and enters the Waldeyer tonsillar ring in the oropharynx and amplifies by initiating a lytic phase. The virus goes on to infect naive B cells in lymphoid tissues, causing their transformation into lymphoblasts and memory B cells. Memory B cells eventually return to the tonsil, where they differentiate into plasma cells, at times, triggering viral replication. The replicated virus remains in saliva as a source of transmission or may infect other B cells [8-10]. 


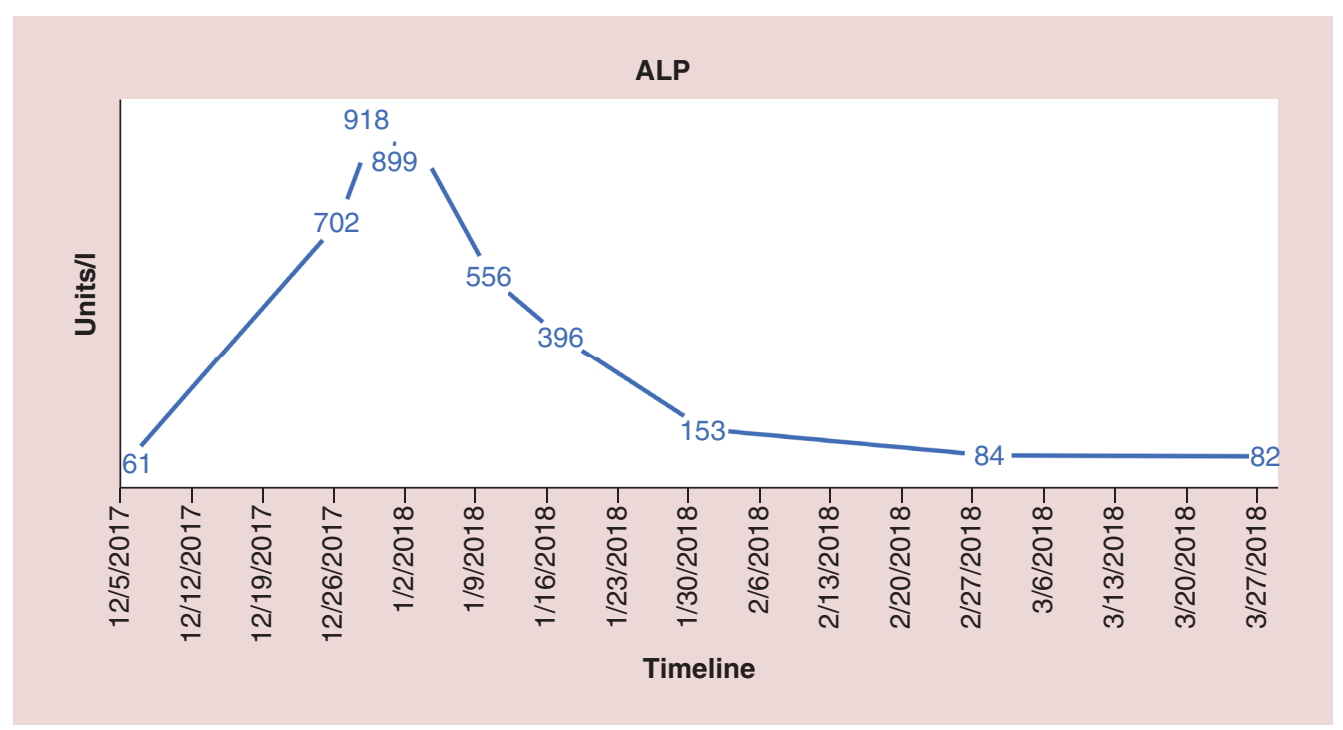

Figure 7. Trend of alkaline phosphatase levels. ALP: Alkaline phosphatase.

Although primary EBV infection occurs during early childhood, infection is usually subclinical or results in mild respiratory symptoms. Acquiring the infection in late childhood or adolescence can manifest as IM, which is reported to occur in approximately $25-75 \%$ of EBV-infected individuals [11-13].

Acute EBV is confirmed by a positive monospot test or EBV serology. As discussed in earlier studies, EBV anti-VCA IgM antibodies are the first humoral response in acute infection. Anti-VCA IgG antibodies peak during the first few months and then persist throughout life. IgG antibodies may present in acute infection, but smaller quantities than anti-VCA IgM [14]. EBV causes latent infection and induces the proliferation of lymphocytes [8] and is considered to have a predilection toward B lymphocytes, but it can also infect $\mathrm{T}$ lymphocytes or epithelial cells as it is reported to be found in some T-lymphoma cells and diseases of epithelial cells [15].

By influencing B-cell growth transcription programs (Latency I-III), EBV may induce tumor formation. Latency I is associated with EBV-related Burkitt lymphoma, Latency II with Hodgkin's disease, T-cell non-Hodgkin's disease, nasopharyngeal and gastric cancer, whereas Latency III is associated with immunocompromised individuals (posttransplant patients and HIV-associated lymphoproliferative disorders) [6,7,16-18]. EBV-positive DLBCL has a poor prognosis when compared with its EBV-negative counterpart [19]. EBV+ DLBCL tends to be diagnosed at an older age, but recent evidence demonstrates that EBV+ DLBCL can be seen in young, immunocompetent individuals leading to the replacement of EBV+ DLBCL of Elderly (DLBCL-E) to EBV+ diffuse large B-cell lymphoma, not otherwise specified (EBV+ DLBCL, NOS) [20-24].

Patients with EBV+ DLBCL, NOS, usually present with an EBV latency pattern III, in which all EBV-associated proteins - like membrane proteins - and nuclear antigens are expressed [25]. Immunosenescence might accelerate in the context of prior EBV infections [26-28].

Presence of Reed-Sternberg-like cells in IM resulting in confusion with Hodgkin's disease is well-known; similar difficulty in excluding NHL especially EBV+ DLBCL can be encountered.

The overlap between the two diseases is discussed in Table 1.

The distinction between IM and lymphoma is made on morphological and clinical grounds. In our patient, the clinical suspicion was the prime motivation in contesting the diagnosis of bona fide malignancy, as hepatic enzymopathy and the rapidly evolving laboratory values made the suspicion for lymphoma less tenable. Refined testing including immunohistochemistry, FISH and flow cytometry provided additional evidence, which resulted in the diagnosis moving away from lymphoma with findings contrary to DLBCL [29-31].

The contents of Table 1 also reiterate that the selflimiting nature of the presentation, combined with findings like positive EBER, negative BCL2 and BCL6, as well as the inversion of the CD4/CD8 ratio derived from advanced testing in our patient, corresponds to the diagnosis of IM. 


\begin{tabular}{|c|c|c|c|}
\hline Disease & IM & EBV-positive DLBCL, NOS & Ref. \\
\hline Clinical features & Clinical triad & B-type symptoms, lymphadenopathy - among others & \\
\hline Extra-nodal & Can be seen occasionally & Usually present & \\
\hline Elevated liver enzymes & Usually & Uncommon & \\
\hline $\lg G, \lg M$ & Can be elevated & Elevated & \\
\hline Lymph node histology & $\begin{array}{l}\text { Polymorphous, may be necrosis; the underlying structure } \\
\text { is retained with reactive infiltrate even with } \\
\text { immunoblastic proliferative features }\end{array}$ & $\begin{array}{l}\text { Polymorphous, with necrosis, destruction of lymph node } \\
\text { architecture but can have partial destruction at times }\end{array}$ & [3] \\
\hline Predominance & T cell & B cell & \\
\hline Expression of EBER & Yes & Not often & \\
\hline BCL 2 & Negative & Positive in $25-80 \%$ & \\
\hline BCL 6 & Negative & Positive in $70 \%$ & \\
\hline CD 19, CD 20, CD 79a & Can be positive & Usually positive & \\
\hline Ki 67 (proliferation fraction) & Can be high & High & \\
\hline CD4/CD8 ratio & Inversion of the ratio $(<1)$ & Inversion is not usually seen & \\
\hline Progression & Selflimiting & Progressive & \\
\hline Treatment & Supportive, resolves in a few weeks & Immunochemotherapy & \\
\hline
\end{tabular}

\section{Conclusion}

IM should be considered in cases of diffuse lymphadenopathy in any population, more so in the elderly and the young where an immunocompromised state can mask the typical presentation of IM. Differentiating between $\mathrm{EBV}+\mathrm{DLBCL}$ and IM is quite challenging considering the extensive overlap in the disease characteristics between the two. Ruling out IM before making a diagnosis of lymphoma is important in guiding appropriate management.

Hence, we suggest testing for acute EBV infection to rule out primary IM in patients with diffuse lymphadenopathy with or without systemic manifestations, even if the clinical picture does not resemble typical IM to avoid misdiagnosis and inappropriate treatment.

\section{Executive summary}

- Here, we present a case of an 83-year-old male with infectious mononucleosis (IM) mimicking Epstein-Barr virus positive diffuse large B-cell lymphoma not otherwise specified. Initial test results including bone marrow biopsy pointed towards lymphoma.

- Further analysis of immunohistochemistry, fluorescence in situ hybridization, and flow cytometry helped exclude lymphoma.

- Also, serology for acute Epstein-Barr virus infection supported the diagnosis of acute IM in our patient.

- Physicians need to differentiate between the atypical presentation of IM and malignancy by careful assessment of history, physical exam and utilizing different molecular techniques to prevent misdiagnosis.

Financial \& competing interests disclosure

The authors have no relevant affiliations or financial involvement with any organization or entity with a financial interest in or financial conflict with the subject matter or materials discussed in the manuscript. This includes employment, consultancies, honoraria, stock ownership or options, expert testimony, grants or patents received or pending, or royalties.

No writing assistance was utilized in the production of this manuscript.

Ethical conduct of research

The authors state that they have obtained appropriate institutional review board approval or have followed the principles outlined in the Declaration of Helsinki for all human or animal experimental investigations. In addition, for investigations involving human subjects, informed consent has been obtained from the participants involved. 


\section{Open access}

This work is licensed under the Attribution-NonCommercial-NoDerivatives 4.0 Unported License. To view a copy of this license, visit: http://creativecommons.org/licenses/by-nc-nd/4.0/

\section{References}

1 Grywalska E, Markowicz J, Grabarczyk P, Pasiarski M, Rolinski J. Epstein-Barr virus-associated lymphoproliferative disorders. Postpy higieny i medycyny doświadczalnej (Online) 67, 481-490 (2013).

2 Louissaint A Jr, Ferry JA, Soupir CP, Hasserjian RP, Harris NL, Zukerberg LR. Infectious mononucleosis mimicking lymphoma: distinguishing morphological and immunophenotypic features. Mod. Pathol. 25(8), 1149-1159 (2012).

3 Childs CC, Parham DM, Berard CW. Infectious mononucleosis. The spectrum of morphologic changes simulating lymphoma in lymph nodes and tonsils. Am. J. Surg. Pathol. 11(2), 122-132 (1987).

4 Kojima M, Kashimura M, Itoh $\mathrm{H}$ et al. Epstein-Barr virus-related reactive lymphoproliferative disorders in middle-aged or elderly patients presenting with atypical features. A clinicopathological study of six cases. Pathol. Res. Pract 203(8), 587-591 (2007).

5 Chan JK, Kwong YL. Common misdiagnoses in lymphomas and avoidance strategies. Lancet Oncol. 11(6), 579-588 (2010).

6 Sbih-Lammali F, Djennaoui D, Belaoui H, Bouguermouh A, Decaussin G, Ooka T. Transcriptional expression of Epstein-Barr virus genes and proto-oncogenes in north African nasopharyngeal carcinoma. J. Med. Virol. 49(1), 7-14 (1996).

7 Niedobitek G, Young LS, Herbst H. Epstein-Barr virus infection and the pathogenesis of malignant lymphomas. Cancer Surv. 30 , 143-162 (1997).

8 Young LS, Rickinson AB. Epstein-Barr virus: 40 years on. Nat. Rev. Cancer 4(10), 757-768 (2004).

9 Thorley-Lawson DA, Allday MJ. The curious case of the tumour virus: 50 years of Burkitt's lymphoma. Nat. Rev. Microbiol. 6(12), 913-924 (2008).

10 Thorley-Lawson DA, Gross A. Persistence of the Epstein-Barr virus and the origins of associated lymphomas. N. Engl. J. Med. 350(13), 1328-1337 (2004).

11 Evans AS. The spectrum of infections with Epstein-Barr virus: a hypothesis. J. Infect. Dis. 124(3), 330-337 (1971).

12 Sawyer RN, Evans AS, Niederman JC, McCollum RW. Prospective studies of a group of Yale University freshmen. I. Occurrence of infectious mononucleosis. J. Infect. Dis. 123(3), 263-270 (1971).

13 Hsu JL, Glaser SL. Epstein-barr virus-associated malignancies: epidemiologic patterns and etiologic implications. Crit. Rev. Oncol. Hematol. 34(1), 27-53 (2000).

14 Epskamp C, De Man P, Libourel EJ. Epstein-Barr virus mimicking lymphoma - a case report. Neth. J. Med. 73(9), 432-434 (2015).

15 Thompson MP, Kurzrock R. Epstein-Barr virus and cancer. Clin.Cancer Res. 10(3), 803 (2004).

16 Cesarman E, Mesri EA. Virus-associated lymphomas. Curr. Opin. Oncol. 11(5), 322-332 (1999).

17 Kis LL, Takahara M, Nagy N, Klein G, Klein E. Cytokine mediated induction of the major Epstein-Barr virus (EBV)-encoded transforming protein, LMP-1. Immunol. Lett. 104(1-2), 83-88 (2006).

18 Klein E, Kis LL, Klein G. Epstein-Barr virus infection in humans: from harmless to life endangering virus-lymphocyte interactions. Oncogene 26(9), 1297-1305 (2007).

19 Beltran BE, Castro D, Paredes S, Miranda RN, Castillo JJ. EBV-positive diffuse large B-cell lymphoma, not otherwise specified: 2020 update on diagnosis, risk-stratification and management. Am. J. Hematol. doi:10.1002/ajh.25760 (2020) (Epub ahead of print).

20 Swerdlow SH, Campo E, Pileri SA et al. The 2016 revision of the World Health Organization classification of lymphoid neoplasms. Blood 127(20), 2375-2390 (2016).

21 Beltran BE, Morales D, Quinones P, Medeiros LJ, Miranda RN, Castillo JJ. EBV-positive diffuse large b-cell lymphoma in young immunocompetent individuals. Clin Lymphoma Myeloma Leuk. 11(6), 512-516 (2011).

22 Lu TX, Liang JH, Miao Y et al. Epstein-Barr virus positive diffuse large B-cell lymphoma predict poor outcome, regardless of the age. Sci. Rep. 5, 12168 (2015).

23 Nicolae A, Pittaluga S, Abdullah S et al. EBV-positive large B-cell lymphomas in young patients: a nodal lymphoma with evidence for a tolerogenic immune environment. Blood 126(7), 863-872 (2015).

$24 \mathrm{Ok} \mathrm{CY}, \mathrm{Ye} \mathrm{Q}$, Li L et al. Age cutoff for Epstein-Barr virus-positive diffuse large B-cell lymphoma - is it necessary? Oncotarget 6(16), 13933-13945 (2015).

25 Castillo JJ, Beltran BE, Miranda RN, Paydas S, Winer ES, Butera JN. Epstein-barr virus-positive diffuse large B-cell lymphoma of the elderly: what we know so far. Oncologist 16(1), 87-96 (2011).

26 Shimoyama Y, Asano N, Kojima M et al. Age-related EBV-associated B-cell lymphoproliferative disorders: diagnostic approach to a newly recognized clinicopathological entity. Pathol. Int. 59(12), 835-843 (2009).

27 Dojcinov SD, Venkataraman G, Pittaluga S et al. Age-related EBV-associated lymphoproliferative disorders in the Western population: a spectrum of reactive lymphoid hyperplasia and lymphoma. Blood 117(18), 4726-4735 (2011). 
28 Gibson SE, Hsi ED. Epstein-Barr virus-positive B-cell lymphoma of the elderly at a United States tertiary medical center: an uncommon aggressive lymphoma with a nongerminal center B-cell phenotype. Hum. Pathol. 40(5), 653-661 (2009).

29 Kaufmann O, Flath B, Spath-Schwalbe E, Possinger K, Dietel M. Immunohistochemical detection of CD10 with monoclonal antibody 56C6 on paraffin sections. Am. J. Clin. Pathol. 111(1), 117-122 (1999).

30 De Leval L, Ferry JA, Falini B, Shipp M, Harris NL. Expression of bcl-6 and CD10 in primary mediastinal large B-cell lymphoma: evidence for derivation from germinal center B cells? Am. J. Surg. Pathol. 25(10), 1277-1282 (2001).

31 McCluggage WG, Catherwood M, Alexander HD, McBride HA, Smith ME, Morris TC. Immunohistochemical expression of CD10 and $\mathrm{t}(14 ; 18)$ chromosomal translocation may be indicators of follicle centre cell origin in nodal diffuse large B-cell lymphoma. Histopathology 41(5), 414-420 (2002). 